\title{
Extensive metabolic and neuropsychological abnormalities associated with discrete infarction of the genu of the internal capsule
}

\author{
F E Chukwudelunzu, J F Meschia, N R Graff-Radford, J A Lucas
}

\begin{abstract}
Objective-The clinical presentation of capsular genu infarct varies. Prominent faciolingual weakness and subcortical dementia are the rule, but symptoms depend on the precise location and extension of the lesion beyond the genu. The aim was to characterise the radiographic, electroencephalographic, and neuropsychometric abnormalities in a woman who had a history of recurrent transient memory loss. Method-Case report.
\end{abstract}

Results-Magnetic resonance imaging showed an infarct in the genu of the left internal capsule. Positron emission tomography scan demonstrated decreased metabolic activity in the ipsilateral temporal, occipitotemporal, and contralateral cerebellar hemispheres. Electroencephalography showed intermittent rhythmic delta activity in the left frontotemporal region, and findings on neuropsychometric evaluation were consistent with cognitive impairment. Follow up evaluation 7 months after the stroke showed improvement in some areas of the cognitive domain, but residual neuropsychometric and neurophysiological abnormalities persisted.

Conclusion-This case illustrates that cerebral and cerebellar diaschisis may contribute to the symptomatic presentation and recovery from capsular genu infarct, although its precise role remains elusive.

(F Neurol Neurosurg Psychiatry 2001;71:658-662)

Neurology,

Luther-Midelfort

Clinic, Eau Claire,

Wisconsin, USA

F E Chukwudelunzu

Department of

Neurology, Mayo

Clinic, 4500 San Pablo

Road, Jacksonville, FL

32224, USA

J F Meschia

N R Graff-Radford

Department of Psychiatry and Psychology

J A Lucas

Correspondence to: Dr N R Graff-Radford graffradford.neill@mayo.edu

Received 13 October 2000 and in revised form

23 April 2001

Accepted 10 May 2001 with dysarthria. Amnestic syndromes may result from lesions of the medial temporal lobe ${ }^{4}$ and diencephalon. ${ }^{5}$ Transient global amnesia ${ }^{6}$ can be easily distinguished from other amnestic syndromes on clinical grounds.

Recurrent transient amnesia limited to recent memory and culminating in ischaemic infarct of the genu of the internal capsule has not been reported. We report on a woman with infarction of the capsular genu who presented with episodic marked cognitive impairment associated with major verbal memory and language deficits. Results of detailed clinical, neuropsychological, and functional imaging studies suggest that cerebral and cerebellar diaschisis may contribute to the presentation and recovery from capsular genu infarction.

\section{Case report}

A 71 year old right handed woman with 12 th grade education presented after acute onset of short term memory loss. Eleven years earlier, she had coronary artery bypass grafting for acute myocardial infarction. Over the previous 2.5 years, she had five discrete episodes of stereotypical short term memory loss, each lasting 15 to 20 minutes and completely resolving. Her fifth spell, 7 months before presentation, was evaluated by brain CT, transoesophageal echocardiography, and carotid duplex ultrasonography at another institution. No abnormality was found, and a diagnosis of transient global amnesia was made. Two days before presentation, while at church, her husband noted that she was unable to follow the service. Later that day, she could not remember her daughter's name or what day it was. The next day, she could not remember the events of the previous 24 hours and asked repetitive questions. Evaluation at the local emergency department a day later disclosed no other focal neurological symptoms. Results of a general physical examination were normal. Abnormal findings on neurological examination were disorientation to time and place and impaired 5 minute delayed recall. Results of laboratory studies, such as glucose, sodium, calcium, leucocyte count, haemoglobin, electrocardiography, and urinalysis, were normal. A diagnosis of transient global amnesia was made, and an outpatient neurological consultation was arranged.

Neurological evaluation 7 days after the onset of her symptoms disclosed no change in her symptoms. She was alert and cooperative but disoriented to place and time. She offered no spontaneous speech. Her response to questions was fluent but notable for delayed 


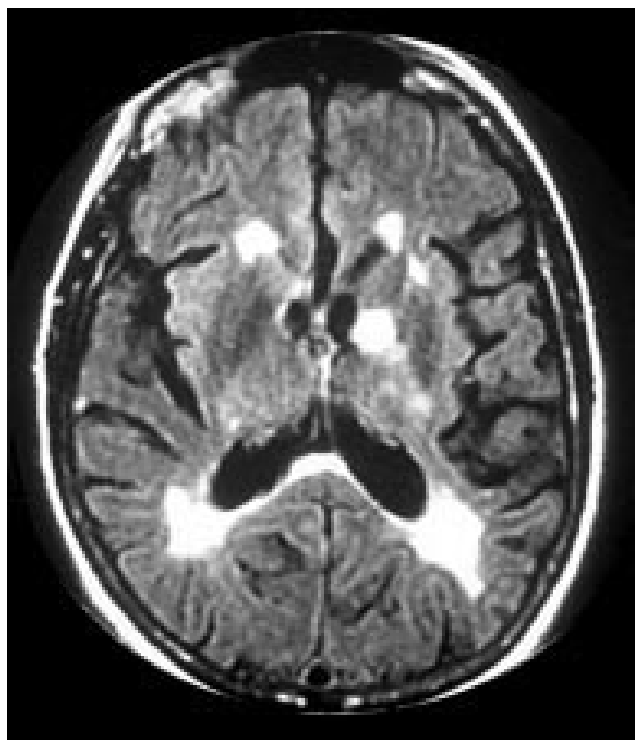

Figure 1 Fluid attenuated inversion recovery magnetic resonance image showing hyperintense signals in the genu of the left internal capsule and periventricular and subcortical white matter.

response latency and word finding difficulties. Comprehension of conversational language was impaired, but she was able to follow a simple one step command. There were marked perseveration, apathy, and psychomotor retardation, with prominent frontal release signs (glabellar, palmomental, and snout). Motor examination showed normal gait with decreased right arm swing, mild drift, and decreased rapid alternating movements of the right hand. There was a mild upper motor neuron right facial weakness. Muscle stretch

Table 1 Neuropsychological test results 2 weeks and 7 months after stroke

\begin{tabular}{|c|c|c|c|c|}
\hline \multirow[b]{2}{*}{ Measures } & \multicolumn{2}{|c|}{2 weeks after stroke } & \multicolumn{2}{|c|}{7 months after stroke } \\
\hline & Raw score & Percentile & Raw score & Percentile \\
\hline \multicolumn{5}{|l|}{ Dementia rating scale (DRS): } \\
\hline Attention & $27 / 37$ & 1 & $30 / 37$ & 2 \\
\hline Initiation, perseveration & $6 / 37$ & $<1$ & $23 / 37$ & $<1$ \\
\hline Construction & $5 / 6$ & 16 & $6 / 6$ & 50 \\
\hline Conceptualisation & $17 / 39$ & $<1$ & $23 / 39$ & $<1$ \\
\hline Memory & $10 / 25$ & $<1$ & $19 / 25$ & 2 \\
\hline Total score & $65 / 144$ & $<1$ & $101 / 144$ & $<1$ \\
\hline \multicolumn{5}{|l|}{ Language: } \\
\hline MAE token test & $22 / 44$ & $<1$ & $27 / 44$ & $<1$ \\
\hline BDAE commands & $11 / 15$ & NA & $13 / 15$ & NA \\
\hline BDAE complex ideational & $3 / 12$ & $<1$ & $6 / 12$ & $<1$ \\
\hline BDAE word repetition & $9 / 10$ & NA & $9 / 10$ & NA \\
\hline BDAE phrase repetition & $13 / 16$ & NA & $16 / 16$ & NA \\
\hline Boston naming test & $16 / 60$ & $<1$ & $29 / 60$ & $<1$ \\
\hline \multicolumn{5}{|l|}{ Acquired verbal skills: } \\
\hline WRAT- 3 reading & $32 / 57$ & 8 & $38 / 57$ & 23 \\
\hline WRAT-3 spelling & $33 / 55$ & 25 & $32 / 55$ & 21 \\
\hline WRAT-3 arithmetic & $24 / 55$ & 5 & $31 / 55$ & 23 \\
\hline PIAT-R reading comprehension & $21 / 84$ & 1 & $24 / 84$ & 1 \\
\hline \multicolumn{5}{|l|}{ Visuospatial abilities: } \\
\hline WAIS-R block design & 16 & 50 & 15 & 37 \\
\hline \multicolumn{5}{|l|}{ Memory: } \\
\hline CERAD learning trial 3 & $4 / 10$ & $<1$ & $4 / 10$ & $<1$ \\
\hline CERAD $10-$ min delay & $0 / 10$ & $<1$ & $2 / 10$ & $<1$ \\
\hline CERAD recog discrimination & $65 \%$ & $<1$ & $65 \%$ & $<1$ \\
\hline WMS-R visual reproduction I & $11 / 41$ & 3 & $15 / 41$ & 14 \\
\hline WMS-R visual reproduction II & $0 / 41$ & 4 & $7 / 41$ & 16 \\
\hline Visual reproduction \% retention & $0 \%$ & $<1$ & $47 \%$ & 9 \\
\hline \multicolumn{5}{|l|}{ Mood: } \\
\hline Geriatric depression scale & $20 / 30$ & NA & $9 / 30$ & NA \\
\hline
\end{tabular}

BDAE=Boston diagnostic aphasia examination; CERAD=Consortium to Establish a Registry for Alzheimer's Disease; MAE=multilingual aphasia examination; NA=normative data not available; PIAT-R=Peabody individual achievement test, revised; WAIS-R=Wechsler adult intelligence scale, revised; WMS-R=Wechsler memory scale, revised; WRAT-3=wide range achievement test, 3rd edition. reflexes were hyperactive, with an extensor plantar response on the right.

She was admitted to hospital, and brain MRI showed T2 weighted and fluid attenuated inversion recovery hyperintense signals in the genu of the left internal capsule and subcortical white matter (fig 1). Gradient echo MRI was negative for cerebral amyloid angiopathy. Electroencephalography showed left frontotemporal intermittent rhythmic delta activity. Transoesophageal echocardiography and magnetic resonance angiography of the intracranial and extracranial vessels yielded normal findings. Cerebrospinal fluid analysis showed 4 white cells and 6 red cells/ $\mu 1$, protein concentration of $41 \mathrm{mg} / \mathrm{dl}$, and glucose concentration of 53 $\mathrm{mg} / \mathrm{dl}$ (serum, $109 \mathrm{mg} / \mathrm{dl}$ ). Results of CSF index, synthesis rate, oligoclonal bands, and fungal and viral cultures were negative.

A neuropsychological examination performed 2 weeks after the onset of her symptoms documented substantial cognitive compromise (table 1). Her performance on an expanded measure of mental status (dementia rating scale $)^{7}$ was severely impaired for her age, with markedly deficient performances on subtests of attention (for example, digit span, visual scanning), initiation/perseveration (for example, word fluency), conceptualisation (for example, identifying oddities and similarities among verbal and visual stimuli), and memory (for example, orientation and immediate memory for words and figures). She was unable to retain information presented in the form of a word list from the Consortium to Establish a Registry for Alzheimer's Disease neuropsychological test battery ${ }^{8}$ or geometric designs from the Wechsler memory scale, revised (visual reproduction). ${ }^{9}$ Severe expressive and receptive language deficits were also evident. She had marked difficulty following auditory-verbal commands on the token test of the multilingual aphasia examination ${ }^{10}$ and comprehending short stories on the complex ideational material subtest of the Boston diagnostic aphasia examination. ${ }^{11}$ Her ability to provide the names of line drawings of objects was also severely impaired (Boston naming test), ${ }^{12}$ with errors characterised primarily by substitution of semantically similar words (for example, "arrow" for "dart," "dice" for "dominoes"). Her written mathematical skill and ability to recognise and pronounce written words were mildly impaired (wide range achievement test, 3rd edition). ${ }^{13}$ Her comprehension of the meaning of written sentences was more severely impaired (Peabody individual achievement test, revised; reading comprehension). ${ }^{14}$ By contrast, the patient showed relatively intact phrase repetition, spelling ability, and visuospatial constructional abilities. She endorsed moderate symptoms of depression on the geriatric depression scale. ${ }^{15}$

${ }^{18} \mathrm{~F}$-2-fluoro-2-deoxy-D-glucose (FDG) positron emission tomography (PET) scan of the brain performed 7 weeks after symptom onset showed decreased metabolic activity in the left temporal, occipitotemporal, and right cerebellar hemispheres (fig 2). The PET scanner used an ADAC vertex coincidence camera with a 

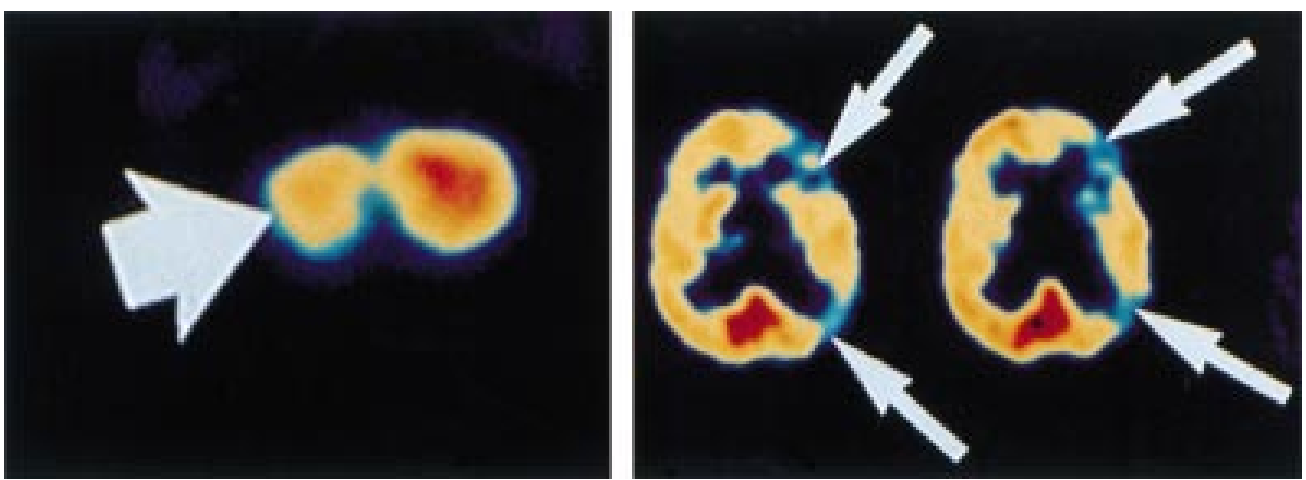

Figure $2 O n{ }^{18} F D G$ positron emission tomography images of the brain; decreased metabolic activity is apparent in the left temporal lobe (long arrows), occipitotemporal lobe (long arrows), and right cerebellar hemisphere (short arrow) 2 weeks after stroke.

matrix resolution of $128 \times 128$. Five millicuries of FDG were administered. Treatment began with $325 \mathrm{mg}$ aspirin, and speech and occupational therapies initiated in the hospital were continued for outpatient management.

Periodic follow up evaluation showed improvement in spontaneous speech, psychomotor retardation, and disorientation at 2 months after the stroke. A repeat neuropsychological evaluation 7 months after her stroke showed improvement in reading recognition, written mathematics skills, and memory for visual information to within normal limits for her age. Improvement was also evident on measures of language comprehension, naming, word fluency, and retention of verbal information; however, these performances remained in the impaired range for her age. No improvement was evident on measures of reading comprehension and verbal learning. Repetition and visuospatial abilities remained within normal limits for her age. Her responses to the geriatric depression scale mood inventory suggested only minimal symptoms of depression at the time of follow up. Table 1 summarises her cognitive assessments at 2 weeks and 7 months after the stroke. A repeat PET study of the brain (5 months later) showed incomplete resolution of the left cortical and right cerebellar hypometabolic defect.

\section{Discussion}

Remote focal metabolic effects in the brain, commonly referred to as diaschisis, are attributed to depressed synaptic activities at sites distant from, but neurally connected with, the damaged area. ${ }^{16}$ Several PET studies have demonstrated these remote metabolic effects in patients with large frontoparietal and thalamocapsular strokes, ${ }^{17-19}$ but the precise relation to patients' symptoms and the prognostic value remain obscure. Some investigators have reported that cerebellar diaschisis does not resolve..$^{20-22}$ Others have suggested that cerebral and cerebellar diaschisis is a transient phenomenon with potential for reversibility of the alterations and recovery of the deficits resulting from it. ${ }^{1723-25}$ Bowler et $a l^{26}$ investigated the contribution of diaschisis to clinical deficit in human cerebral infarction and concluded that diaschisis does not independently add to clinical deficit after stroke. However, other investigators have found that crossed cerebellar diaschisis is greater with larger infarcts, ${ }^{21}{ }^{27}$ but whether the degree of crossed cerebellar diaschisis correlates with clinical stroke severity remains controversial. Speculations that these remote effects underlie the neuropsychological deficits of subcortical origin ${ }^{28}$ and contribute to diffuse symptoms of acute supratentorial strokes, such as confusion, agitation, and coma, have been difficult to prove. ${ }^{18} 29-31$

Frontotemporal cortices have extensive connections with ipsilateral anterior thalamic nuclei and contralateral cerebellar hemisphere via the anterior and inferior thalamic peduncles. Corticothalamic and thalamocortical fibres form the thalamic peduncles. These fibres enter and exit the thalamus at its rostral and caudal poles and along the dorsal surfaces. ${ }^{32} 33$ The inferior thalamic peduncle carrying fibres connecting the ventromedial thalamus with the orbitofrontal, insular, and temporal cortices passes through the posterior capsule in the region of the genu. ${ }^{2}$ Damage to this white matter tract may occur with infarction in the region of the inferior genu, causing severe amnesia from disruption of the basolateral limbic system. ${ }^{34}{ }^{35}$ Interruption of the anterior or inferior thalamic peduncle, or both, in the region of the capsular genu has been proposed as the mechanism underlying the abrupt cognitive impairment seen in these patients. ${ }^{2}$

Functional brain imaging in our patient demonstrated hypometabolic activity in the temporal cortex ipsilateral to the capsular lesion, supporting the view that cognitive changes probably occurred by functional disruption, perhaps related to diaschisis. Periventricular and subcortical T2 signal abnormalities (leukoaraiosis) were present on brain MRI in our patient. Leukoaraiosis or white matter rarefaction has been reported to occur at a higher frequency in subjects with mild cognitive deficits and decreased mental processing. ${ }^{36}$ According to one study, about one sixth of patients with stroke had pre-existing dementia previously undiagnosed, and leukoaraiosis and other factors were found to be independent 
Table 2 Summary of case reports of isolated capsular genu infarcts

\begin{tabular}{|c|c|c|c|c|}
\hline Authors, year & $\begin{array}{l}\text { No. of } \\
\text { patients }\end{array}$ & Symptoms at presentation & $\begin{array}{l}\text { Recurrent } \\
\text { symptoms }\end{array}$ & Location of lesion \\
\hline Tatemichi et al, $1992^{2}$ & 1 of 6 & Right hemiparesis, confusion & No & Left capsular genu \\
\hline Bogousslavsky and Regli, $1990^{1}$ & 5 & Faciolingual weakness, dysarthria, dysphagia & No & Right (2) and left (2) capsular genu \\
\hline Rousseaux et al, $1987^{38}$ & 1 & Left hemiparesis & No & Right capsular genu \\
\hline Iwata, $1984^{39}$ & 1 & Right hemiparesis & No & Left capsular genu, corona radiata \\
\hline Schnider et al, $1996^{40}$ & 1 & Confusion, amnesia & No & Right capsular genu, anterior thalamus \\
\hline Yamanaka et al, $1996^{41}$ & 2 & Abulia & No & Right (1) and left (1) capsular genu \\
\hline Moreaud et al, $1996^{42}$ & 1 & Abulia, confusion, right facial weakness & No & Left capsular genu \\
\hline Lai et al, $1990^{43}$ & 1 & Amnesia & No & Left capsular genu \\
\hline Terao et al, $1991^{44}$ & 1 & Amnesia & No & Left capsular genu \\
\hline Yamadori, $1990^{45}$ & 1 & Aphasia & No & Left capsular genu \\
\hline Spertell and Ransom, $1979^{46}$ & 1 & Dysarthria, clumsy hand syndrome & No & Left capsular genu \\
\hline Kooistra and Heilman, $1988^{34}$ & 1 & Memory loss & No & Left capsular genu \\
\hline Markowitsch et al, $1990^{35}$ & 1 & Aphasia, right hemiparesis & No & Left capsular genu \\
\hline Chukwudelunzu et al, present case & 1 & Amnesia & Yes $(\times 5)$ & Left capsular genu \\
\hline
\end{tabular}

predictors of poststroke dementia. ${ }^{37}$ Leukoaraiosis and the possible coexistence of previously undiagnosed mild dementia may be contributing factors in this case.

Review of the English literature uncovered 13 case reports of isolated capsular genu infarcts. ${ }^{12343538-46}$ None of the patients had stereotypic spells of marked cognitive impairment before infarction as seen in our patient. Among the 13 patients, amnesia was the major presenting feature in four ${ }^{40}{ }^{43-45}$ A lesion was seen in the left genu of the internal capsule in three of the four patients. Table 2 summarises the literature review of cases. Tatemichi et al reported detailed clinical and neuropsychological long term follow up (10 weeks to 2 years) findings in four of their six patients with capsular genu infarct. Resolution of acute dementia syndrome occurred in only one patient 2 years after stroke. Results of initial brain functional imaging studies $\left({ }^{133} \mathrm{Xe}\right.$ regional cerebral blood flow and single photon emission computed tomography (SPECT)) were abnormal in all patients, but follow up studies were not reported. Schnider et $a l^{40}$ reported on a patient with persistent abnormal neuropsychological testing results 7 months after a capsular genu stroke. In a case report by Moreaud et al, ${ }^{42}$ PET demonstrated hypometabolism in the left frontotemporoparietal, left caudate, left thalamus, and right cerebellar cortices 2 months after a left capsular genu infarct. Follow up SPECT studies in two patients reported by Yamanaka et $a l^{41}$ showed persistent abnormality in one and resolution in the other 4 and 6 months after stroke, respectively. Kooistra and Heilman ${ }^{34}$ and Markowitsch et $a l^{35}$ reported similar cases with persistent cognitive abnormalities on neuropsychological testing 2 years and 9 months after capsular genu infarction. Our case report is similar to previously reported cases, but in addition to long term follow up with detailed clinical and neuropsychological testing, we showed that clinical and neuropsychological findings were correlated with those of PET studies.

In our patient, the relevant lesion lies in the distribution of anterior perforators arising from the apex of the internal carotid artery ${ }^{47} 48$ or the anterior cerebral artery. ${ }^{48}{ }^{49}$ The essential features of this capsular genu "cognitive syndrome" resemble the clinical profile found in unilateral polar thalamic infarction ${ }^{50}$ or the dementia syndrome of bilateral paramedian thalamic infarction. ${ }^{52}$ Among 100 patients with lacunar infarcts in the territory of deep perforators of the carotid system identified by CT, Ghika et $a p^{3}$ found neuropsychological deficits in up to $34 \%$. Thus, capsular genu infarct causing acute cognitive impairment may not be uncommon and may be underreported.

A chance association between the infarct and our patient's presentation cannot be excluded with certainty. Her underlying cardiac condition may have contributed to her memory loss. It is also possible that our patient had transient epileptic amnesia ${ }^{54}$ and that the infarct was coincidental. A trial of anticonvulsant drugs and ambulatory electroencephalography were not performed.

Although our patient's disorientation, apathy, psychomotor retardation, and mood and some of her cognitive functions improved 7 months after the stroke, neuropsychological evaluation and PET studies showed persistent abnormalities beyond the area of the structural lesion. The infarct was limited to the white matter without involvement of the adjacent grey matter structures. No mass effect to adjacent structures was demonstrated on brain MRI. The implications are that the cerebral and cerebellar diaschisis in this patient may have contributed to her inadequate clinical recovery. This case supports the phenomenon of cerebral diaschisis as a possible contributing mechanism to poor recovery from a small but strategically placed ischaemic infarct.

1 Bogousslavsky J, Regli F. Capsular genu syndrome. Neurology 1990;40:1499-502.

2 Tatemichi TK, Desmond DW, Prohovnik I, et al. Confusion and memory loss from capsular genu infarction: a thalamocortical disconnection syndrome? Neurology 1992;42: 1966-79.

3 Donnan GA, Bladin PF, Berkovic SF, et al. The stroke syndrome of striatocapsular infarction. Brain 1991;114:51-70.

4 Corkin S. Lasting consequences of bilateral medial temporal lobectomy: clinical course and experimental findings in lobectomy: clinical course and exp

5 Graff-Radford NR, Tranel D, Van Hoesen GW, et al. DienGraff-Radford NR, Tranel D, Van Hoesen
cephalic amnesia. Brain 1990;113:1-25.

6 Hodges JR, Warlow CP. The aetiology of transient global amnesia. A case-control study of 114 cases with prospective follow-up. Brain 1990;113:639-57.

7 Mattis S. Dementia rating scale. Odessa, Florida: Psychological Assessment Resources, 1988.

8 Welsh KA, Butters N, Mohs RC, et al. The Consortium to Establish a Registry for Alzheimer's Disease (CERAD). Part V. A normative study of the neuropsychological battery. Neurology 1994;44:609-14.

9 Wechsler D. Wechsler memory scale— revised. New York: The Psychological Corporation, 1987.

10 Benton AL, Hamsher KdeS, Sivan AB. Multilingual aphasia examination. 3rd ed. Iowa City, Iowa: AJA Associates, 1994. 11 Goodglass H, Kaplan E. The assessment of aphasia and related Goodglass $\mathrm{H}$, Kaplan E. The assessment of aphasia and rel
disorders. 2nd ed. Philadelphia: Lea and Febiger, 1994.

12 Kaplan E, Goodglass H, Weintraub S. Boston naming test. Philadelphia: Lea and Febiger, 1983. 
13 Wilkinson GS. Wide range achievement test. 3rd rev. Wilmington, Delaware: Wide Range, 1993.

14 Markwardt FC Jr. Peabody individual achievement test: PIAT-R revised ed. Circle Pines, Minnesota: American Guidance Service, 1989.

15 Yesavage JA, Brink TL, Rose TL, et al. Development and validation of a geriatric depression screening scale: a preliminary report. F Psychiatric Res 1982-3;17:37-49.

16 Feeney DM, Baron JC. Diaschisis. Stroke 1986;17:817-30.

17 Kushner M, Alavi A, Reivich M, et al. Contralateral cerebellar hypometabolism following cerebral insult: a positron emission tomographic study. Ann Neurol 1984;15:425-34

18 Pappata S, Mazoyer B, Tran Dinh S, et al. Effects of capsular or thalamic stroke on metabolism in the cortex and cerebellum: a positron tomography study. Stroke $1990 ; 21$. 519-24.

19 Andrews RJ. Transhemispheric diaschisis. A review and comment Stroke 1991;22:943-9.

20 Infeld B, Davis SM, Lichtenstein M, et al. Crossed cerebellar diaschisis and brain recovery after stroke. Stroke 1995;26:90-5.

21 Pantano P, Baron JC, Samson Y, et al. Crossed cerebellar diaschisis. Further studies. Brain 1986:109:677-94.

22 Miura H, Nagata K, Hirata Y, et al. Evolution of crossed cerebellar diaschisis in middle cerebral artery infarction. $\mathcal{F}$ Neuroimaging 1994;4:91-6.

23 Perani D, Di Piero V, Lucignani G, et al. Remote effects of subcortical cerebrovascular lesions: a SPECT cerebral perfusion study. F Cereb Blood Flow Metab 1988;8:560-7.

24 Pappata S, Tran Dinh S, Baron JC, et al. Remote metabolic effects of cerebrovascular lesions: magnetic resonance and positron tomography imaging. Neuroradiology 1987;29:1-6.

25 Pantano P, Lenzi GL, Guidetti B, et al. Crossed cerebella diaschisis in patients with cerebral ischemia assessed by SPECT and ${ }^{123}$ I-HIPDM. Eur Neurol 1987;27:142-8.

26 Bowler JV, Wade JP, Jones BE, et al. Contribution of diaschisis to the clinical deficit in human cerebral infarction. Stroke 1995;26:1000-6.

27 Meneghetti G, Vorstrup S, Mickey B, et al. Crossed cerebellar diaschisis in ischemic stroke: a study of regional cerebral blood flow by ${ }^{133} \mathrm{Xe}$ inhalation and single photon emission blood flow by ${ }^{133} \mathrm{Xe}$ inhalation and single photon emission computerized

28 Metter EJ, Wasterlain CG, Kuhl DE, et al. FDG positron emission computed tomography in a study of aphasia. Ann Neurol 1981;10:173-83.

29 Baron JC, D'Antona R, Pantano P, et al. Effects of thalamic stroke on energy metabolism of the cerebral cortex. A positron tomography study in man. Brain 1986;109:1243-59.

30 Karbe H, Herholz K, Szelies B, et al. Regional metabolic correlates of Token test results in cortical and subcortical left hemispheric infarction. Neurology 1989;39:1083-8.

31 Perani D, Vallar G, Cappa S, et al. Aphasia and neglect after subcortical stroke. A clinical/cerebral perfusion correlation study. Brain 1987;110:1211-29.

32 Robertson RT, Kaitz SS. Thalamic connections with limbic cortex. I. Thalamocortical projections. F Comp Neurol 1981;195:501-25.

33 Irle E, Markowitsch HJ. Connections of the hippocampal formation, mamillary bodies, anterior thalamus and cingu-
late cortex. A retrograde study using horseradish peroxilate cortex. A retrograde study using horser
dase in the cat. Exp Brain Res 1982;47:79-94.

34 Kooistra CA, Heilman KM. Memory loss from a subcortical white matter infarct. F Neurol Neurosurg Psychiatry 1988;51 $866-9$
35 Markowitsch HJ, von Cramon DY, Hofmann E, et al. Verbal memory deterioration after unilateral infarct of the internal capsule in an adolescent. Cortex 1990;26:597-609.

36 Pantoni L, Garcia JA. The significance of cerebral white matter abnormalities 100 years after Binswanger's report. A review. Stroke 1995;26:1293-301.

37 Henon H, Pasquier F, Durieu I, et al. Pre-existing dementia in stroke patients. Baseline frequency, associated factors, and outcome. Stroke 1997;28:2429-36.

38 Rousseaux M, Lesoin F, Quint S. Unilateral pseudobulbar syndrome with limited capsulothalamic infarction. Eur Neurol 1987;27:227-30.

39 Iwata $M$. Unilateral palatal paralysis caused by lesion in the corticobulbar tract. Arch Neurol 1984;41:782-4.

40 Schnider A, Gutbrod K, Hess CW, et al. Memory without context: amnesia with confabulations after infarction of the right capsular genu. F Neurol Neurosurg Psychiatry 1996;61: $186-93$.

41 Yamanaka K, Fukuyama H, Kimura J. Abulia from unilateral capsular genu infarction: report of two cases. 7 Neurol Sci 1996;143:181-4.

42 Moreaud O, Charnallet A, David D, et al. Frontal lobe syndrome after a left genu capsular infarction. Eur Neurol 1996;36:322-4.

43 Lai C, Okada Y, Sadoshima S, et al. A case of left internal capsular infarction with auditory hallucination and peculiar amnesia and dysgraphia. No To Shinkei 1990;42:873-7. (In Japanese.)

44 Terao Y, Bandou M, Nagura H, et al. Persistent amnestic syndrome due to infarction of the genu of the left internal capsule. Rinsho Shinkeigaku 1991;31:1002-6. (In Japanese.)

45 Yamadori A. Does circumscribed ischemic white matter lesion produce neuropsychological symptoms? Clin Neurol 1990;30:1348-50.

46 Spertell RB, Ransom BR. Dysarthria: clumsy hand syndrome produced by capsular infarct. Ann Neurol 1979;6: 63-5.

47 Ghika JA, Bogousslavsky J, Regli F. Deep perforators from the carotid system. Template of the vascular territories. Arch Neurol 1990;47:1097-100.

48 Dunker RO, Harris AB. Surgical anatomy of the proximal anterior cerebral artery. F Neurosurg 1976;44:359-67.

49 Kashihara M, Matsumoto K. Acute capsular infarction. Location of the lesions and the clinical features. Neuroradiology 1985;27:248-53.

50 Graff-Radford NR, Eslinger PJ, Damasio AR, et al. Nonhemorrhagic infarction of the thalamus: behavioral, anatomic, and physiologic correlates. Neurology 1984;34:1423.

51 Bogousslavsky J, Regli F, Assal G. The syndrome of unilateral tuberothalamic artery territory infarction. Stroke 1986; $17: 434-41$.

52 Guberman A, Stuss D. The syndrome of bilateral paramedian thalamic infarction. Neurology 1983;33:540-6.

53 Ghika J, Bogousslavsky J, Regli F. Infarcts in the territory of the deep perforators from the carotid system. Neurology 1989;39:507-12

54 Zeman AZ, Boniface SJ, Hodges JR. Transient epileptic amnesia: a description of the clinical and neuropsychological features in 10 cases and a review of the literature. $f$ Neurol Neurosurg Psychiatry 1998;64:435-43. 